
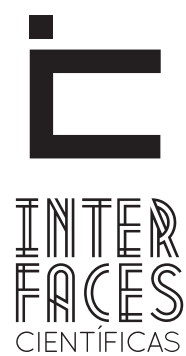

EDUCAÇ̃̃O

ISSN IMPRESSO 2316-333X

ISSN ELETRÔNICO 2316-3828

Internacional

\title{
CINE SOCIAL E INTERCULTURALIDAD: UNA PROPUESTA DIDÁCTICA
}

\author{
María Rocio Cobo Piñero
}

\section{RESUMEN}

El presente artículo expone las posibilidades didácticas del cine desde un punto de vista que fomenta el análisis intercultural, poniendo el acento en las ventajas de usar cortometrajes de tema social en cursos de lengua y cultura. La primera parte del estudio, presenta brevemente las distintas corrientes teóricas relacionadas con el soporte visual en el aula de español para extranjeros y pone de manifiesto la carencia de un análisis intercultural del medio fílmico. La segunda parte, está compuesta por la didactización de dos cortometrajes españoles de
2005, premiados y bastante aclamados: Nana y Éramos Pocos. Las actividades que proponemos pretenden desarrollar la competencia intercultural así como la mirada crítica del alumnado ante dos realidades sociales: el sexismo y la inmigración.

\section{PALABRAS CLAVE}

Cine. Cortometraje. Análisis intercultural. Sexismo. Inmigración. 


\section{RESUMO}

O presente artigo expõe as possibilidades didáticas do cinema desde um ponto de vista que promove o enfoque intercultural, e centra-se no uso de curtas-metragens de tema social nos cursos de língua e cultura. A primeira parte do estudo, apresenta brevemente as distintas correntes teóricas relacionadas com o suporte visual na aula de espanhol para estrangeiros e evidencia a carência de uma análise intercultural do meio fílmico. A segunda parte, está composta pela didatização de dois curtas-metragens espanhóis do ano

\section{ABSTRACT}

This article presents the didactic possibilities of using movies from a socio-cultural perspective. It focuses on the advantages of employing short-films that deal with social issues in language and culture courses. The first part of the analysis presents an overview of the studies related to the use of media in the Spanish as a foreing language classroom and highlights the lack of an intercultural approach to films. The second part, proposes a didactic model for two highly acclaimed Spanish short films from
2005, premiados e de bastante prestigio: Nana e Éramos Pocos. As atividades que propomos pretendem desenvolver a competência intercultural assim como a mirada crítica do alunado diante duas realidades sociais: o sexismo e a imigração.

\section{PALAVRAS CHAVE}

Cinema. Curta-metragem. Análise intercultural. Sexismo. Imigração.

2005: Nana and Eramos Pocos. The aim of the activities that conform the teaching materials is to develop the intercultural skills of students, as well as their critical look at two social situations: sexism and immigration.

\section{KEY WORDS}

Film. Short film. Intercultural analysis. Sexism. Immigration. 


\section{INTRODUCCIÓN: EL SOPORTE VISUAL EN EL AULA}

El objetivo de este artículo es presentar las posibilidades didácticas del cine social, y en especial de los cortometrajes, con miras a fomentar la interculturalidad y el análisis crítico de dos realidades socioculturales: la inmigración y el sexismo. Para ello propondremos dos modelos de unidad didáctica, a partir de una metodología que prioriza el "enfoque por tareas", dirigidas no solamente al uso comunicativo de la lengua sino también a la reflexión. Entendemos la educación intercultural como una práctica educativa que sitúa las diferencias culturales de individuos y de grupos como centro de la reflexión y de la indagación educativa, desde premisas que respetan y valoran el pluralismo cultural (AGUADO ODINA, 2005, p. 29-30). El "enfoque por tareas" es un método didáctico que busca el aprendizaje integrado de lengua y cultura por medio de actividades/tareas que facilitan el uso de la lengua de manera comunicativa (DÍAZ-CORRALEJO CONDE, 2008, p. 245). ${ }^{2}$

Desde la última década del siglo XX, se ha publicado profusamente sobre el uso del soporte visual en el aula de español para extranjeros (ELE) ${ }^{3}$. Los primeros artículos publicados versan sobre el uso del vídeo y de la televisión en general, así como las ventajas que de ello se derivan. Uno de los estudios que inician esta corriente en España es el de Bustos (1997) en el que el autor desglosa las ventajas y desventajas del uso del video en el aula, además de proponer una clasificación de los distintos tipos de actividades que se pueden llevar a cabo a través de este medio. Bustos da cuenta de tres tipos de dinámicas: 1) la práctica de detección, que comporta el desarrollo de ejercicios de observación lingüística; 2) la práctica de comprensión, en la que se insta a los aprendientes a que interpreten elementos no verbales a partir de gestos y miradas el tipo de actividad de partida suele conllevar

2. Uno de los pioneros en desarrollar este método de aprendizaje de lenguas, basado en tareas comunicativas, es el influyente lingüista australiano David Nunan (1998).

3. Este trabajo se centra en la literatura publicada en España. una presentación de la escena sin sonido o que, por el contrario, descifren pistas verbales en este segundo caso, el mensaje se escucha con sonido y después se hacen preguntas de comprensión. 3) El tercer y último tipo de dinámica que propone es la práctica de expresión a partir de tres tipos de tareas: la predicción, la dramatización y la conversación. En palabras de Bustos "el mayor rendimiento del vídeo se muestra en su uso como punto de partida para la realización de actividades destinadas al desarrollo de la expresión lingüística, sobre todo oral, pero también escrita” (1997, p. 102). Por tanto, es evidente el énfasis en la práctica lingüística, en detrimento del ámbito cultural ${ }^{4}$.

Otros autores analizan las ventajas del uso del cine en las clases de ELE, especialmente en base a las películas del director Pedro Almodóvar; entre ellos, los más citados son Díaz Torrecillas (1993) o Pérez Torraba (1994). En estas investigaciones se presenta el uso fragmentado del cine, ya que algunos autores defienden abiertamente la utilización de secuencias aisladas de películas. Ciertamente, el empleo de secuencias de filmes ha supuesto la base metodológica de los escasos manuales especializados que se han publicado hasta la fecha en España. Uno es los primeros manuales que utiliza el soporte fílmico como material complementario es el de Santos Gargallo (2001), cuyo énfasis reside en las funciones lingüísticas más que en el ámbito sociocultural. Más recientemente Aixalá y Álvarez (2009) han diseñado un completo manual en el que trabajan con fragmentos de doce largometrajes españoles y latinoamericanos producidos entre 1998 y 2007. En dicha compilación didáctica, los aspectos culturales reciben mayor atención que en los anteriores ejemplares.

Asimismo, impera una corriente teórica que analiza el uso pragmático de los fragmentos de películas, argumentando que "cada secuencia cinematográfica es una

\footnotetext{
4. En este sentido, Larrañaga Domínguez (2001) utiliza las dinámicas propuestas por Bustos (1997), cuya consecución está relacionada con el visionado de programas de televisión.
} 
muestra real y auténtica de comunicación en su género que se nos presenta como una herramienta genuina para ilustrar la selección y el uso de distintas muestras de lengua" (LOSADA ALDREY, 2009, p.31). La autora examina unidades fraseológicas en la película Todo sobre mi madre, de Pedro Almodóvar. Para ello, divide las expresiones idiomáticas en ocho, dependiendo de la temática y de los usos comunicativos ${ }^{5}$. En la misma línea, Cuesta Estévez (2000) plantea el uso pragmático de los tacos y las palabras malsonantes en el filme Los peores años de nuestra vida. Estévez selecciona un fragmento de diez minutos de la película para explotar los coloquialismos de acuerdo con la situación. Propone actividades de comprensión y de creación: adivinar el final de la historia, continuar una secuencia o inventar el diálogo de una escena sin sonido, rellenar huecos de un diálogo transcrito con nuevo léxico, etc. La secuenciación de actividades, efectivamente, consigue el objetivo marcado: la práctica lingüística y pragmática de coloquialismos utilizados frecuentemente en el español.

Un trabajo bastante completo sobre las posibilidades del cine en el aula de ELE es el de Carmen Rojas Gordillo (2002), que además completa su propuesta con una historia del cine español por géneros y etapas. Este artículo podría iniciar al mundo del cine español a los que no estén familiarizados con el mismo y necesiten de una base teórica e histórica. Por último, Rojas Gordillo sugiere una serie de tareas relacionadas con la familia española y cita varias películas en las que se trata este tema para ejemplificar cómo utilizar el cine como fuente de información cultural. Los dos anexos que inserta son bastante útiles por recoger un muestrario de decenas de películas españolas relacionadas con la historia y la literatura.

\section{MENOS ES MÁS: EL USO DIDÁCTICO DE LOS CORTOMETRAJES}

Los primeros artículos que consideran específicamente el trabajo con cortometrajes en el aula de ELE, datan de la primera década del siglo XXI y no son muy

5. Coincidiendo con Losada Aldrey en el punto de partida de su investigación, Díaz Perez (1993) estudió la comunicación jergal en los guiones cinematográficos de Almodóvar. numerosos ${ }^{6}$. Los exiguos análisis planteados, ponen el acento en el uso de léxico (concretamente del español jergal) y en el lenguaje más que en aspectos socioculturales. Una característica común a todos ellos es que redundan en explicar, de manera pormenorizada, las ventajas del uso de los cortos en el aula; en ocasiones, esta justificación se convierte en el tema central del estudio. Otros autores, se ciñen a la didactización de uno o varios cortometrajes, véanse los trabajos de Pérez Torraba (2007) o Casa Núñez (2007).

A pesar de que dichos estudios conforman la base teórica del presente análisis, se intentará añadir una perspectiva apenas tratada en lo publicado hasta la fecha: el enfoque sociocultural e intercultural como punto de partida de la selección y posterior didactización de los cortometrajes elegidos7. Este enfoque se suele considerar de manera transversal y no como eje vertebrador del estudio. Los pocos autores que toman como punto de partida el ámbito sociocultural, presentan más bien experiencias empíricas de cómo plantear una clase a través del cine para justificar su uso en el aula. Una autora que verdaderamente se ciñe al enfoque sociocultural en su uso del medio cinematográfico en la enseñanza de ELE es Myriam Criado (2009), que además incluye en su investigación del cine hecho por mujeres varios cortometrajes de carácter documental.

En cuanto a los criterios de selección de los cortometrajes, Gimeno Ugalde (2008) expone cuatro criterios de selección de acuerdo a una serie de pa-

\footnotetext{
6. El cortometraje se define como "cualquier filme de tres rollos o menos y una duración inferior a 30 minutos" (KONINGSBERG, 2004, p. 144). El auge del género se inicia en España en la década de los noventa, gracias a la difusión en festivales de cine y a que directores consagrados como Iciar Bollaín, Isabel Coixet o Vicente Aranda decidan rodar en este formato.

7. El Marco Común de Referencia Europeo (MCRE) define el conocimiento sociocultural como "el conocimiento de la sociedad y de la cultura de la comunidad o comunidades en las que se habla el idioma meta [] tiene la importancia suficiente como para merecer la atención del alumno, sobre todo porque, al contrario que muchos otros aspectos del conocimiento, es probable que no se encuentre en su experiencia previa y puede que esté distorsionado por los estereotipos" (2002, p. 103-4). EL MCRE ha sido un referencial crucial para insertar el conocimiento sociocultural en la enseñanza de ELE en España.
} 
rámetros: i) criterios pedagógicos (autenticidad del cortometraje e interés del alumnado); ii) criterios didácticos (capacidad educativa y corta duración de los cortometrajes que no superan los 30 minutos); iii) criterios temáticos (contenidos socioculturales e histórico-políticos así como la dimensión intercultural) y, iv) criterios lingüísticos. Este último criterio de selección ha sido el más extendido entre los docentes:

\begin{abstract}
Al valorar cualquier material, casi de manera automática, nos planteamos las exigencias lingüísticas que presenta para el aprendiente, si contiene las estructuras que queremos trabajar, etc. Sin duda, este aspecto es importante pero nunca debe ser el único criterio para seleccionar el material audiovisual, ya que de ese modo se perdería el gran potencial que se esconde detrás de las imágenes de una película. (GIMENO UGALDE, 2008).
\end{abstract}

Justamente, nuestro criterio de selección es el temático y más concretamente, el que atiende a los aspectos socioculturales e interculturales.

A la luz de la literatura publicada sobre la materia, el enfoque del presente trabajo puede considerarse novedoso por ahondar en la manera de presentar en clase dos temas socioculturales concretos: el sexismo y la inmigración. Abordaremos los temas a través de las piezas cinematográficas seleccionadas, tomando el ámbito sociocultural como protagonista del análisis. El uso lingüístico será circunstancial y se ceñirá más bien al que haga el alumnado al debatir sobre los contenidos, predomina por tanto una explotación del ámbito cultural, que fomenta la interculturalidad y la comparación entre la C2 y la C1 del alumnado desde un punto de vista crítico que cuestione y analice las situaciones sociales presentadas ${ }^{8}$. A este respecto, Gordillo Álvarez indica que el cortometraje es muy eficaz a la hora de tratar cuestiones socioculturales así como temas de calado social:

por un lado, el distanciamiento que permite la organización discursiva de un relato que no corresponde a la actualidad informativa, sino que se vertebra a partir

8. Nomenclatura usada por Vázquez Tavares para referirse a la cultura de origen del alumno (C1) y a la extranjera (C2). de configuraciones de ficción [] por otro se produce una proximidad potenciada por los fenómenos relacionados con la identificación narrativa, que acercan e individualizan tanto los temas como los personajes. (GORDILLO ÁLVAREZ, 2008, p. 4).

A tenor de lo expuesto por Gordillo Álvarez, el soporte ficcional propicia el distanciamiento del alumnado, a la par que favorece establecer paralelismos entre los personajes de la narración fílmica y los mismos estudiantes. Por consiguiente, será más factible tratar los temas sociales a través de un medio que a priori, se presenta como ficcional. Esta premisa, nos facilitará también activar mecanismos de crítica en los discentes ante las realidades sociales representadas para que consideren la presencia de estereotipos y desigualdades relacionadas con el sexo, la raza, la clase y el lenguaje ${ }^{9}$.

\section{1. ÉRAMOS POCOS}

El primer cortometraje seleccionado es Éramos Po$\cos$ (BORJA COBEAGA, 2005) por los buenos resultados que se consiguen en las clases de ELE a la hora de analizar cuestiones socioculturales, tanto con niveles básicos como avanzados. La fácil adaptabilidad a distintos niveles se debe no sólo a la brevedad de la cinta (característica aplicable a todos los cortometrajes) sino también a la carga descriptiva de las imágenes y de los diálogos; breves e incisivos. El humor ácido del corto desdramatiza los temas sociales que presenta: el sexismo, la educación/perpetuación de roles estereotipados, el papel de las abuelas en la sociedad y las residencias para la tercera edad en España. Los protagonistas de la historia son cuatro: el padre indolente; el hijo adolescente que sigue los pasos de su padre asumiendo el mismo rol pasivo; la madre ausente que ha abandonado el hogar cansada de la situación y por último, la suegra-abuela, a la que recogen del asilo para que "cuide" de ellos encargándose de las tareas domésticas.

9. Adoptaremos una mirada crítica en el marco de la lingüística crítica aplicada al discurso (ACD). Cruz Moya (2004) esboza la influencia de la perspectiva crítica y sus repercusiones tanto en la lingüística como en la enseñanza de ELE. 
Otro aspecto que se puede destacar del cortometraje es el tono irónico, que a veces provoca la risa ante la representación del mundo que han creado los personajes masculinos y del que escapa la madre. Los recursos de los que se vale el director para conseguir la sátira son los diálogos cargados de ironía, las imágenes y la música. Durante los escasos 16' minutos de duración de la pieza, los alumnos se involucran en la historia, llevados por la comicidad de los personajes que en ocasiones, roza la parodia. La música contribuye a esta sátira -a causa de su carácter optimista y desenfadado-, junto con el inesperado desenlace del corto, que no sólo afianza la ironía, sino que también motiva la crítica de la situación retratada. La abuela, a la que habían sacado del asilo, no es en realidad quien pensaban, sino una mujer mayor que vive en la residencia y que asume el papel de abuela con tal de escapar del entorno deprimente del asilo. Cuando el padre se da cuenta del equívoco al final del filme, en lugar de hacérselo saber a su hijo, prefiere continuar con la pantomima porque les conviene ser atendidos por la abuela "postiza". La exageración a la que recurre el director para desarrollar la trama, funciona como catalizador entre el alumnado, al que le resulta más fácil analizar y reconocer cada ámbito temático. El desenlace de la película favorece un análisis crítico de las situaciones sociales y motiva una comparación entre estas realidades con las de su país de origen. Un valor añadido al cortometraje es el haber sido nominado al Oscar al mejor cortometraje de ficción en 2005 y el atesorar 80 premios.

El tema del sexismo ha captado la atención de directores/as de cine en los últimos tiempos y se han estrenado tanto películas como cortometrajes que retratan la problemática, adoptando diferentes ópticas. En el caso de los cortometrajes, destacamos los dirigidos por Icíar Bollaín Por tu bien (sobre la apropiación del cuerpo femenino durante el parto) y Amores que matan (acerca de la violencia de género) ${ }^{10}$; el dirigido

10. Betina Hermoso (2005) acomete una interesante didactización de la película de Icíar Bollaín Te doy mis ojos para acercar al alumnado la Ley Orgánica de protección integral contra la violencia de género en España. por Azucena de La Fuente Sueño de una mujer despierta (sobre la violencia doméstica); Cartas a Nora de Isabel Coixet (sobre la invisibilidad de la inmigración femenina) y El orden de las cosas, de los hermanos Esteban Alenda (una aterradora metáfora sobre la violencia machista). Igualmente, la crítica fílmica española se ha hecho eco de las representaciones de la mujer en la gran pantalla, más aún en la última década:

El cine y la televisión en sus vertientes de ficción, entretenimiento o publicidad transmiten valores, modelos y actitudes y, cómo no, determinadas representaciones de género que refuerzan, mantienen o transgreden los estereotipos de masculinidad y feminidad. (SANGRO, 2009, p. 20).

\subsection{NANA}

El segundo cortometraje elegido para su explotación didáctica es Nana (RODRÍGUEZ MELCÓN, 2005). De un lado, su brevedad (3 minutos) hace que sea un material muy adecuado para introducir el tema de la inmigración en España. De otro, al tratarse de una pieza en la que no hay diálogos sino únicamente imágenes, puede adaptarse perfectamente a cualquier nivel de lengua. El poder visual del corto es extraordinario e incita al alumnado al análisis y a la reflexión. Precisamente, esa carencia de diálogos, lo convierte en un material sumamente valioso para despertar la conciencia crítica de los aprendices. El director de Nana ha querido introducir unas imágenes más cercanas y humanas para que el punto de partida sea ponerse en el lugar del otro, sin prejuicios.

La actitud que se demanda del espectador radica en entender los motivos por los que alguien está dispuesto a arriesgar su vida y la de su bebé para ir en busca de un futuro mejor. El lenguaje que emplea es universal: una nana. Los iconos son reconocibles: una patera en la que navegan personas de tez negra y el mar. Incluso cuando no se informa a los estudiantes de que el tema de la clase será 
la inmigración, inmediatamente después de ver el filme, reconocen los iconos y los relacionan con la inmigración. Ya cuentan con un bagaje mediático al respecto; lo interesante es saber qué tipo de información han recibido e inquirirles sobre ello. Bañón Hernández asegura que los medios se encargan de relacionar la inmigración con la marginación y la exclusión social a través de determinados mecanismos discursivos; "el marco discursivo más frecuente cuando se trata de inmigración y exclusión social: compromiso, reivindicación, discriminación, condescendencia y prevención" (2003, p. 38-39).
Del mismo modo que Rodríguez Melcón, otros cineastas españoles han plasmado en la última década su visión personal sobre la inmigración. En el caso que nos ocupa los cortometrajes encontramos ejemplos representativos en: Yo (no) soy de aquí (ARRIAGA, 2003), Español para extranjeros (GARCÍA SÁNCHEZ, 2004), Proverbio chino (SAN ROMÁN, 2005), Hiyab (SALAS, 2005) y El viaje de Said (RIOBOÓ, 2006). Sin embargo, la explotación didáctica de dicho material es escasa y el acercamiento intercultural a tales piezas fílmicas tampoco se ha producido, lo que abre un campo de investigación casi sin explorar en el marco del español para extranjeros.

\section{DIDACTIZACIÓN}

\section{Cortometraje 1: Éramos Pocos}

\section{Objetivos culturales:}

Conocer el "síndrome de las abuelas esclavas" ${ }^{11}$

Reflexionar sobre el sexismo en España.

Comparar los aspectos socioculturales tratados con Brasil.

Fomentar la capacidad crítica de los aprendices.

\section{Objetivos funcionales:}

Saber argumentar.

Proponer soluciones a un problema.

Expresar probabilidad.

Nivel: Intermedio B1, estudiantes universitarios.

Metodología: Enfoque por tareas

Temporalización: 2 sesiones de 60 minutos.

Materiales: Cortometraje Éramos Pocos, artículo de El País “Imposible conciliar sin abuelos” <http://www.elpais. com/articulo/sociedad/Imposible/conciliar/abuelos/elpepisoc/20080315elpepisoc_1/Tes>

11. Término clínico de reciente acuñación. Según el cardiólogo Guijarro Morales, el síndrome de la abuela esclava es “una enfermedad grave, que afecta a mujeres maduras sometidas a una sobrecarga física y emocional, que origina graves y progresivos desequilibrios, tanto somáticos como psíquicos" (2001, p. 10). 


\section{Secuenciación de actividades}

\section{Antes de ver el corto}

Lluvia de ideas: palabras relacionadas con la vejez y con la juventud.

¿Qué quiere decir el título de la película? ${ }^{12}$

Lectura del artículo "Imposible conciliar sin abuelos". En parejas (A / B), cada uno lee una parte del artículo para compartir después las ideas más relevantes relacionadas con el género, el sexismo y la sociedad.

\section{Durante el visionado}

\section{Hasta el min. 2.22'}

¿Quién es la mujer que se va de casa?

¿Por qué?

\section{Hasta el min. 12.08'}

Describe a padre e hijo. Utiliza al menos 5 adjetivos para cada uno.

¿Por qué van a la residencia de ancianos?

¿Cómo es la residencia? ¿Se parece a alguna en la que hayas estado?

\section{Después del visionado}

¿Cómo interpretas el final de la historia?

¿Por qué crees que la abuela se quedó en la casa?

¿Cómo relacionas el artículo leído anteriormente y la historia narrada?

¿Qué intención tiene el director del corto? ¿Qué medios usa para ello?

Tarea final: preparar una presentación de 10 minutos. Repartir los temas en parejas:

Propuesta de soluciones al problema de las "abuelas esclavas".

El sexismo en la sociedad. Ejemplos del corto y de experiencias propias.

Los abuelos en España y en otras sociedades: comparación.

\section{Cortometraje 2: Nana}

Objetivos culturales:

Reflexionar sobre las migraciones en España y en los países de origen del alumnado.

Fomentar la capacidad crítica de los aprendices.

Analizar los estereotipos relacionados con la inmigración a través de los medios de comunicación.

Objetivos funcionales:

Saber plantear ventajas y desventajas al fenómeno de la inmigración

Expresar opinión. 
Nivel: Avanzado B2, estudiantes universitarios.

Metodología: Enfoque por tareas

Temporalización: 2 sesiones de 60 minutos.

Materiales: Cortometraje Nana, titulares de noticias, canción “Papeles Mojados” de Chambao.

\section{Secuenciación de actividades}

\section{Antes de ver el corto}

a. ¿Qué palabras suelen estar asociadas con la inmigración en los medios de comunicación de Brasil? Aquí tienes algunas que aparecen en los medios españoles: cayuco, patera, "sin papeles", crisis, Ley de Extranjería, Guardia Civil, integración, expulsión, paso del Estrecho, ilegal, tolerancia/intolerancia.

b. Lee y comenta los siguientes titutales de prensa (en parejas) ${ }^{13}$ :

Los intentos de cruzar el Estrecho se disparan en octubre. Fuente: EL PAIS. 28/10/2012.

La salida acelerada de españoles al extranjero hace caer la población.

Fuente: EL PAIS. 15/10/2012.

Muere ahogado un bebé que viajaba en una patera junto con otros 13 inmigrantes. Fuente: ABC. 8/10/2012.

“Me echaron de un examen y del instituto por llevar “hiyab"'. Fuente: EL MUNDO. 11/10/2011.

c. ¿Qué relación tiene el título del corto con la inmigración? ${ }^{14}$

\section{Después de ver el cortometraje}

¿Qué imagen se da de los inmigrantes en el cortometraje? ¿Con qué recursos?

¿En qué idioma canta la protagonista?

Escucha la canción de Chambao “Papeles Mojados” y lee la letra. ¿Está relacionada con el corto? ¿Por qué? Utiliza al menos 5 ejemplos.

Analiza en parejas el lenguaje metafórico de la letra de “Papeles Mojados”. ¿Puedes deducir el significado de las siguientes expresiones?

miles de sombras, frío que pela, ahogan sus penas, la mar se echó a llorar, se hunden sus sueños, papeles mojados, calaos ${ }^{15}$ hasta los huesos, una bocaná de aire.

\section{Tarea final: debate}

- Cada alumno/pareja de alumnos asumirá uno de los siguiente roles para expresar su punto de vista: moderador/a, inmigrante, político conservador/a, asociación de inmigrantes, profesor/a de escuela con alto porcentaje de inmigrantes, madre de inmigrante (ella se ha quedado en el país de origen), periodista.

- Hacer un listado de ideas relacionadas con el rol asignado.

13. En clase, se pueden revisar titulares de periódicos brasileños para comparar el tratamiento del tema de la inmigración entre los dos países.

14. Seguramente relacionarán el título con las nanas que cuidan niños. En este caso, podremos analizar los estereotipos referidos a las ocupacio-

nes de las personas inmigrantes en diferentes países y a la escasez de oportunidades en otros destinos.

15. Se debe hacer referencia al cambio de la terminación -ado por -ao y -ada por -á en la pronunciación andaluza. 


\section{CONSIDERACIONES FINALES}

Tras demostrar la carencia de estudios didácticos que prioricen el conocimiento intercultural al usar el cine en las clases de español para extranjeros, se han seleccionado dos cortometrajes para después proponer una serie de actividades de práctica con fines comunicativos (tareas). El objetivo de las mismas, ha sido activar el análisis crítico de dos realidades socioculturales, a través de distintas estrategias: la comparación entre la C2 y la C1 de los discentes; la reflexión sobre cuestiones relacionadas con la identidad, así como la influencia de los medios de comunicación en forjar determinadas imágenes estereotipadas. En definitiva, se ha presentado un modelo de trabajo que, a través de tareas comunicativas y de reflexión, busca una mejor comunicación intercultural, para que el alumnado pueda comprender las diferencias culturales que le separan de la C2 e intentar ser más tolerante con la cultura en principio desconocida.

Otro de los objetivos propuestos en este artículo, ha sido demostrar la idoneidad de los cortometrajes para tratar temas sociales, desde un punto de vista intercultural. De un lado, se produce un distanciamiento inicial en el alumnado al tratarse de un medio de ficción no un documental o reportaje periodístico y de otro, se da una identificación narrativa que facilita el tratamiento de los temas presentados: la inmigración y el sexismo. Las temáticas sociales que en un principio pudieran parecer alejadas de la realidad de los aprendientes, se tornan más cercanas tras el visionado de las piezas cortas. Las unidades didácticas presentadas han propuesto tareas comunicativas, a partir del visionado de los cortometrajes, en las que el conocimiento intercultural protagoniza el aprendizaje, en detrimento del análisis de estructuras lingüísticas que se ha venido practicando en la enseñanza de español para extranjeros.

\section{REFERENCIAS}

AGUADO-ODINA, Teresa y GIL JAURENA, Inés. Educación intercultural: una propuesta pata la transformación de la escuela. Madrid: Editorial Catarata, 2005.

AIXALÀ, Evelyn y ÁLVAREZ, Gabriela (Org.). Clase de Cine: Actividades para la visualización de películas en español. Barcelona: Difusión, 2009.

DÍAZ TORRECILLAS, Aurora. El estímulo cinematográfico: desarrollo de destrezas comunicativas y valor cultural. In: IV CONGRESO INTERNACIONAL DE ASELE, 7, 1993, Madrid. Problemas y Métodos en la Enseñanza del Español como Lengua Extranjera. Madrid: Universidad Complutense de Madrid, 1994. $p$ 537-552.

BAÑÓN HERNÁNDEZ, Antonio Miguel. Análisis crítico del discurso sobre la inmigración: a propósito de la representación de los actores comprometidos. Interlingüística, Madrid, v. 14, p. 15-31, 2003.

BUSTOS, José Manuel. Aplicaciones del vídeo a la enseñanza de español como lengua extranjera. Carabela, Madrid, v. 42, p. 93-105, 1997.

CASA NÚÑEZ, Juan. Dos propuestas de explotación de cortometraje: Blanco y negro y El sueño de la maestra. III FORO DE PROFESORES DE E/LE, 2007. Valencia: Universidad de Valencia, 2008, p. 537-552.

CRIADO, Myriam. El cine de mujeres como recurso didáctico en la enseñanza de cultura española contemporánea en el aula de ELE. RedELE, Madrid, v. 16, jun. 2009, disponible en: <http://www.educacion.es/redele/RevistaJunio09/Cine\%20de\%20 mujeres\%20como\%20recurso\%20didactico.pdf> Consultado: 10 mar. 2011. 
CRUZ, Olga. Aportaciones de la lingüística crítica a la enseñanza del español como lengua extranjera. In: RUHSTALLER, Stefan y LORENZO, Francisco (Org.). La competencia lingüística y comunicativa en el aprendizaje del español como lengua extranjera. Madrid: Edinumen, 2004. p. 61-70.

CUESTA ESTÉVEZ, Gaspar. El español coloquial y el cine actual: una experiencia práctica. X CONGRESO DE ASELE, 1999, Cádiz. Nuevas Perspectivas en la enseñanza del español como lengua extranjera. Cádiz: Universidad de Cádiz, 2000. p. 861-870.

DÍAZ-CORRALEJO, Joaquín. Aportaciones de la didáctica a las lenguas y culturas. 2ed. In: SÁNCHEZ LOBATO, Jesús y SANTOS GARGALLO, Isabel (Org.). Vademécum de la formación de profesores: Enseñar español como segunda lengua (L2)/lengua extranjera. Madrid: Editorial SGEL, 2008.

DÍAZ PÉREZ, Juan Carlos. Presencia de la comunicación jergal en la enseñanza de español para extranjeros: los guiones cinematográficos de Pedro Almodóvar. IV CONGRESO INTERNACIONAL DE ASELE, 1993, Madrid. Problemas y Métodos en la Enseñanza de Español como Lengua Extranjera. Madrid, SÁNCHEZ, Jesus (Org.), 1994. p. 469-478.

GIMENO UGALDE, Esther. Trabajar con cortos en el aula de LE/L2: secuencia didáctica para Éramos Pocos. RedELE, Madrid, v. 14, oct. 2008, disponible en: <http://www.educacion.es/redele/Revista14/Martinez_sonia_cortometraje_junio_2008.pdf> Consultado: 18 oct. 2012 .

GORDILLO ÁLVAREZ, Inmaculada. El cortometraje y las minorías étnicas. Comunicación y Ciudadanía, Sevilla, v. 6, p. 2-23, 2008.

GORDILLO ÁLVAREZ, El diálogo intercultural en el cine español contemporáneo: entre el estereotipo y el etnocentrismo. Comunicación y Ciudadanía, Sevilla, v. 3, p. 207-222, 2007.
GUIJARRO MORALES, Antonio. El síndrome de la abuela esclava. Granada: Universidad de Granada, 2001.

HERMOSO GÓMEZ, Betina. ¡Una de cine! El cine como acercamiento a los problema sociales: Te doy mis ojos. RedELE, Madrid, v. 4, jun. 2005, disponible en: <http:// www.educacion.gob.es/dctm/redele/Material-RedEle/Revista/2005_04/2005_redELE_4_05Hermoso.pd f?documentld=0901e72b80e00247> Consultado: 7 nov. 2012.

KONINGSBERG, Ira. Diccionario Técnico Akal de Cine. Madrid: Akal, 2004.

LARRAÑAGA DOMÍNGUEZ, A. La televisión en el aula de E/LE: Propuestas prácticas para el desarrollo de la comprensión auditiva. Carabela, Madrid, v. 49, p. 5576, 2001.

LOSADA ALDREY, María Carmen. Fraseología y cine: Contextualización dinámica de unidades fraseológicas. Boletín de la Asociación de ASELE, Logroño, v. 41, nov. 2009, disponible en: <http://formespa.rediris. es/pdfs/asele41.pdf> Consultado: 5 nov. 2012.

MARCO COMÚN EUROPEO DE REFERENCIA PARA LAS LENGUAS: APRENDIZAJE, ENSEÑANZA, EVALUACIÓN, Madrid: Ministerio de Educación Cultura y Deporte, 2002. Disponible en: <http://cvc.cervantes. es/ensenanza/biblioteca_ele/marco/> Consultado: 6 nov. 2012.

NUNAN, David. El diseño de tareas para la clase comunicativa. Madrid: Edinumen, 1998.

PÉREZ TORRABA, Luis. El corto en la clase de ELE. RedELE, Madrid, v. 10, jun. 2007, disponible en: <http:// www.educacion.es/redele/revista10/PerezTobarra. pdf> Consultado: 4 nov. 2012.

ROJAS GORDILLO, Carmen. El cine español en la clase de ELE: una propuesta didáctica. Actas $\mathbf{X}$ Congre- 
so Brasileño de profesores de español. Consejería de Educación de Brasil. Disponible en: <http://www. ub.es/filhis/culturele/rojas.html> Consultado: 25 oct. 2012.

SANGRO, Pedro y PLAZA, Juan (Org.). La representación de las mujeres en el cine y la televisión contemporáneos. Barcelona: Laertes, 2009.

SANTOS GARGALLO, Isabel. De cine. Fragmentos cinematográficos para el aula de ELE. Madrid: SGEL, 2001.

VÁZQUEZ TAVARES, Laura. El cine como vehículo de cultura en la clase de ELE. Frecuencia ELE, Madrid, v. 32, p. 36-44, 2006.

\section{CORTOMETRAJES}

ARRIAGA, Javier. Yo (no) soy de aquí, 2003. Disponible en: <http://www.youtube.com/watch?v=TDfytzne Cl4\&feature $=$ related $>$

BOLLAín, Icíar. Amores que matan, 2000. Disponible en: <http://www.nodo50.org/filosofem/spip. php?article60>

Por tu bien, 2004. Disponible en: <http://www. elpais.com/comunes/2004/haymotivo/>

Recebido em: 17 de Fevereiro de 2014
COBEAGA, Borja. Éramos Pocos, 2005. Disponible en: <http://www.youtube.com/watch?v=YQ9txWq3Ae8>

COIXET, Isabel. Cartas a Nora, 2007. Disponible en: <http://www.youtube.com/watch?v=MO3bMnvRkSE>

DE LA FUENTE, Azucena. Sueño de una mujer despierta. España, Productora Confío, 2003.

ESTEBAN ALENDA, Hermanos. El orden de las cosas, 2010. Disponible en: <http://www.elpais.com/articulo/cultura/orden/machista/ elpepucul/20100506elpepucul_10/Tes>

GARCÍA SÁNCHEZ, José Luis. Español para extranjeros, 2004. Disponible en: <http://www.elpais.com/ comunes/2004/haymotivo/director_22.html>

RIOBOÓ, Coke. El viaje de Said. 2007. Disponible en: <http://www.youtube.com/watch?v=mF_ZSCxIAIU>

RODRÍGUEZ MELCÓN, José Javier. Nana, 2005. Disponible en: <http://www.rebelion.org/noticia. php?id=41818>

SALAS, Xavi. Hiyab, 2005. Disponible en: <http:// www.youtube.com/watch?v=10TcXyEhr_o>

SAN ROMÁN, Javier. Proverbio chino, 2005. Disponible en: <http://www.youtube.com/watch?v=EpXfHrnghAk>

1. Doctoranda de la Universidad de Sevilla, España (Programa de Literatura en Lengua Inglesa) en cotutela internacional con la Universidade Federal do Espírito Santo- UFES- (Programa de Letras).

E-mail: rociocobo@gmail.com 